\title{
Economic Policy Making for Environmental Problems as an Interactive Learning Process ${ }^{1}$
}

M P de Wit

Centre for Scientific and Industrial Research, Pretoria

\section{ABSTRACT}

The foremost limitation of public policy approaches is that the context of the public policy problem is not taken into account. In the case of complex and dynamic environmental problems, such as global climate change, there is a need for a framework for approaching economic policy that takes account of the complexity and changing realities of such problems. The objective of this paper is to present a framework to approach economic policy making in a case of such complex and dynamic environmental problems. The literature on economic and public policy theories, the need for a systematic policy design process and approaches to complexity and dynamics in policy making is framework available to one where the focus is on the best learning process to facilitate economic policy making on complex and dynamic environmental problems. Based on sociological models of experiential leaming, a multiple-loop learning framework (MLLF) is presented. This model illustrates the importance of orchestrated science-policy interactions through interactive learning. The opportunities and limitations of this model are discussed with reference to the debate on economic policy for global climate change.

JEL Q20, Q28, Q38

\section{INTRODUCTION}

The sheer complexity and dynamics of global environmental problems, such as climate change, has opened an intensive debate on the approaches of various economic theories to environmental policy making. It is realized that climate change is also an economic problem as scarce resources are either vulnerable to climate change or have to be allocated to the mitigation of climate change (Nordhaus, 1991; Cline, 1992; Fankhauser, 1995; Bruce, Lee \& Haites, 1996; IPCC, 2001). The question, however, is whether various economic decisionrules are necessary and sufficient to inform economic policy on global climate change, and how this should be done. 
The objective of this paper is to answer the question of how economic policy making for complex and dynamic environmental problems can best be approached. In section 2 the underlying positivistic economic philosophy and its implications for approaching policy making is discussed with reference to various economic theories on the environment. In section 3 it is emphasized that a systematic policy design process is needed that can take account of complex and dynamic policy problems. In section 4 the literature on existing approaches to complexity and dynamics in policy making for sustainable development is reviewed which sets the scene for the development of policy learning framework in section 5 . In section 6 a few words are said about current economic policy making approaches to climate change and the need for the application of an interactive learning process. Section 7 concludes.

\section{FROM ECONOMIC THEORY ON THE ENVIRONMENT TO POLICY MAKING}

The flourishing economic-philosophical argument is that economics is a welldefined science underpinned by realistic assumptions. This positive approach to economic problems is definitive and realism cannot be an independent criterion (see Hahn \& Hollis, 1979: 2). The application of the positive economic approach to policy making was outlined by Keynes (1917) in his book The scope and method of political economy. He urged the importance of "recognising a distinct positive science of political economy" (Friedman 1953: 3). The stage was set for the further development of economic political theory and, therefore, subsequently economic policy making approaches to issues pertaining to the natural environment. To paraphrase Friedman (1953:4):

Positive economics is in principle independent of any particular ethical position or normative judgements. As Keynes says, it deals with "what is", not with "what ought to be". Its task is to provide a system of generalisations that can be used to make correct predictions about the consequences of any change in circumstances. Its performance is to be judged by the precision, scope, and conformity with experience of the predictions it yields. In short, positive economics is, or can be, an "objective" science, in precisely the same sense as any of the physical sciences.

The link between economics and scientific objectivity has been made and translated into the realm of economic approaches to policy through specific welfaristic decision rules such as Pareto optimality. Such approaches have been standard in approaching economic policy issues ever since. 
Positivistic economics accepts the scientific objectivity (what is or what might be), or the ethical neutrality, of economics (Bromley, 1991: 207). Normative economics is perceived as connoting value-laden arguments (what ought to be). According to Blaug (1992: 112) one can best think of this as a distinction between scientific economics and practical advice on economic policy. Inspired by the philosopher David Hume (1711-76), the perception of a watertight distinction between the realm of facts and the realm of values was bom and further developed within positivistic economics.

The methodology of positive economics, however, has not remained unchallenged in economic thinking. Several scholars have asked questions on the nature of and the assumptions underlying positive economics (Hahn \& Hollis, 1979; Blaug, 1992, 1980; Boland, 1982; Caldwell, 1982; Eichner, 1983; Bromley, 1991, 2000). Blaug (1992, 1980) and Caldwell (1982) come to the conclusion that economics cannot claim to be scientifically objective and ethically neutral. Ward (1972) argues "that economics is basically a normative science adoming itself with the fig leaf of hard-headed positivism" (as quoted in Blaug, 1992: 238). The distinction between what is and what ought to be in such problems, cannot be separated easily. Positivistic economics became divorced from value-judgements and too many values were treated as basic or were simply ignored (Sen, 1970). There is no real value-free social science. Economy is partly ideology, and a separation of the positive from the normative in developing economic theory is impossible. Approaching economic policy to complex and dynamic problems would involve a rethink on Keynes' positive science of political economy.

The implications of such a statement on policy making are significant (Bromley, 1991: 212). The positivistic policy research programme in economics has concentrated on an apparently value-free way of participating in the policy debate. The resulting new welfare economics, with efficiency as evidence of scientific objectivity, however, is controversial. Blaug $(1980 ; 147-8)$ concluded that "the concept of Pareto optimality ... should not be confused with theorems of positive economics...immense confusion has been sown on matters of 'efficiency' without committing ourselves to any value judgements". The search in welfare economics for a fixed order for the collective choice process is frustrated by the complexity of policy making. Bromley (1991: 217) describes this search for a fixed order as reductionistic decision rules. According to Bromley (1991: 217), the persistent debate on the appropriate welfare criterion and on the Boadway paradox, in which the ability of the gainers to compensate the losers does not lead to an unambiguous improvement in social welfare (Boadway, 1974), is testimony to this complexity. Efficiency on the policy level is a value-laden concept in itself. This change in economic thinking, especially on the level of policy making, forces a recognition of the complexities in the collective choice process. 
Now that the apparent simplistic theory-policy relationship from positivistic economic approaches has been questioned, the next question is what alternative public policy approaches could add to the debate. Schneider and Ingram (1997: xi) identify four prominent theories that have guided politics and policy during most of the twentieth century: the pluralistic theory, policy sciences, public choice, and critical theories. Schneider and Ingram (1997: 10-11) conclude that not one of these public policy approaches "have provided an adequate diagnosis, explanation, or prescription for public policy and that their central failures include a narrow knowledge orientation, insufficient attention to policy design, and a failure to recognise the central role social constructions have in determining the characteristics of policy designs". The foremost limitation of these policy approaches is the assumption that the context of the public policy problem is not taken into account, i.e. one design fits all, thereby creating an imbalance in the other values policy must serve (Schneider \& Ingram 1997: 10).

The point that public policy, and more specifically environmental policy, is context-specific has also been pointed out by other scholars. According to Gunningham and Grabosky (1998: 32): "So complex and various are the causes of environmental degradation and the circumstances in which they arise that no single instrument, and indeed no single mix of instruments, could conceivably be successful in addressing all or even most of them. The optimal policy could only be determined on a case-by-case basis". Opschoor and Tumer (1994) state that $a$ priori rules are inferior to case-by-case analysis. Stemer (1994: 7) argues that the choice of "[a] policy instrument ... depends crucially on both the institutional setting and on the exact nature of the environmental problem at hand".

Nevertheless, most economic theories on the environment link most closely with the public choice approach to public policy. In't Veld and Kraan (1991) present a useful overview of different public choice models, distinguishing between radical public choice, individual moralism, constitutional economics and a hybrid of these three, namely, moderate public choice:

In the radical public choice model, the neoclassical model with a homo economicus is extended to the political process without any adjustments for the realities of the political process. Brennan and Buchanan (1985: xi) describe this model as one attempting to offer a pure science of politics that is fully analogous to the science of markets. According to them the objective is "to derive testable hypotheses about the effects of specific changes in basic parameters on observed political results".

In the model of individual moralism political behaviour is predominantly determined by moral motives, in contrast to the economic behaviour of homo economicus. The task of political theory is to clarify the choices people are making in terms of their belief systems and to improve the contents of these belief systems themselves (In't Veld \& Kraan 1991: 3). Empirical work is 
directed at description and analysis of prevailing political belief systems. Brennan and Buchanan (1985: ix) describe this model as being concemed with "analytical esoterica in the modelling of alternative political arrangements". Modem welfare theory with its emphasis on the development of the social welfare function determined by normative criteria such as economic efficiency or sustainability, is an example of this public choice model.

- The basic claim in the model as developed by Buchanan $(1991,1987)$, namely constitutional economics, is that theoretical analysis should proceed in different ways for different kinds of political decisions. The fundamental distinction is between decisions at the constitutional level of choice and the post-constitutional level of choice. The first type of decision determines the legal-institutional-constitutional structure of the polity, while the second type of decision determines the economic and political process within a given structure (Buchanan, 1987). In post-constitutional decision making the model of homo economicus applies. At the level of constitutional choice (choice about institutional rules) decision makers are susceptible to what In't Veld and Kraan (1991: 4) label normative reasoning. However, individual choice remains dependent on the institutional-constitutional constraints (Buchanan, 1989). The overall objective is "to understand the workings of alternative political institutions so that choices among such institutions (or structures of rules) can be more fully informed" (Bremnan \& Buchanan 1985: xi).

- The model of moderate public choice is closer to the radical public choice model in that it appreciates the relevance of positive economic analysis for a broader area of economic decision making than constitutional economics tend to do (In't Veld \& Kraan 1991: 5). On the other hand, individual moralism is more accepted in that there is some room for normative reasoning at the post-constitutional level of choice. In some areas of postconstitutional choice, moral motives can be decisive for the behaviour of citizens, politicians and bureaucrats. This model builds on the model of constitutional economics, but pleads for a more realistic mix of positive analysis and normative reasoning.

The next question is how these public policy theories relate to economic theories on economic-environment interactions. It can be expected that the different economic theories on the environment have different inclinations towards a certain, or more than one, public policy model. It is important to link economic theories on the environment to public policy models so as to lose no useful insights into policy design through the ex ante choice of a particular public policy paradigm. In Table 1 an attempt is made to link economic theories on the environment to public policy models. This is an early attempt, as most economic theories on the environment, especially ecological economics, are in early phases of development. 
Table 1 Economic theories on the environment and public policy models

\begin{tabular}{|l|c|c|c|c|c|c|}
\hline & \multicolumn{3}{|c|}{ Public choice } & Pluralism & $\begin{array}{c}\text { Political } \\
\text { science }\end{array}$ & $\begin{array}{c}\text { Critical } \\
\text { theories }\end{array}$ \\
\hline & Radical & $\begin{array}{c}\text { Individual } \\
\text { moralism }\end{array}$ & $\begin{array}{c}\text { Constitu- } \\
\text { tional } \\
\text { economics }\end{array}$ & & & \\
\hline $\begin{array}{l}\text { Environmental } \\
\text { Economics }\end{array}$ & $\mathrm{x}$. & $\mathrm{X}$ & & & & \\
\hline $\begin{array}{l}\text { Ecological } \\
\text { Economics }\end{array}$ & & $\mathrm{X}$. & $\mathrm{x}$. & & $\mathrm{x}$. & \\
\hline $\begin{array}{l}\text { Neo-institu- } \\
\text { tional } \\
\text { economics }\end{array}$ & $\mathrm{x}$ & $\mathrm{x}$ & $\mathrm{X}$. & & & \\
\hline $\begin{array}{l}\text { Evolutionary } \\
\text { approaches }\end{array}$ & & & & $\mathrm{X} ?$ & & \\
\hline
\end{tabular}

Source: De Wit (2001: 114)

The focus on optimisation within a particular setting and according to a set of pre-determined normative criteria, such as economic efficiency (in the case of environmental economics) or sustainability (in the case of ecological economics), excludes an unconditional acceptance of the status quo (pluralism) or a total rejection of the status quo (critical theory).

The evolutionary approach, however, comes closest to accepting processional realities $^{2}$ as a foundation for theoretical development, but the reviewed literature does not support the uncritical acceptance of the status quo. The lack of focus on optimisation rules out any connection with public choice models and political science. It can be hypothesised that some elements of critical theory, such as the emphasis on social change, are aligned with evolutionary approaches, but no conclusions can be made at this stage.

Both environmental economic and neo-institutional approaches are extensions of positivistic neoclassical economic theory. In this approach the theory of homo economicus could be extended to the public policy arena, as in the radical public choice approach. Some free marketeers within the environmental economic and neo-institutional approaches follow this approach (Anderson \& Leal, 1991; Anderson \& Hill, 1995). This is the exception rather than the rule, as most environmental economic scholars follow assumptions based on (new) welfare economics. Through their emphasis on economic efficiency, these theories are more inclined to follow the welfaristic approach of individual moralism. The difference is that neo-institutional approaches are closely aligned 
with constitutional economics, while environmental economics is not. In constitutional economic theory the co-existence of political and market institutions are accepted by definition, which aligns closely to the neoinstitutional notion of a variety in property right structures. None of these institutions is left in its black box, as environmental economists tend to do with the political process (see Hahn (1989) for this critique on environmental economic policy making). No literature was found to support the alignment of environmental economics or neo-institutional economics with one of the nontraditional economic approaches to public policy. In summary, environmental economists are clearly linked to public policy by individual moralism, while neo-institutional economists align more closely with a mix of constitutional economics and individual moralism, but with an emphasis on the former.

Ecological economic approaches take a cautious approach to environmental degradation, distrusting in general the ability of markets to provide a sustainable solution. Although a better defined role for both markets and governments is accepted when compared to the environmental economic approach, the realities of the political process itself are not effectively internalised. Daly $(1992,1999)$ suggests a logical sequence of policy tasks: defining scale and distribution in a political process and leaving the allocation of resources, within these constraints, to the market. Peet $(1992: 220-21)$ refers to this sequence as a policy hierarchy, since, in his view, "ethical and ecological principles are the true determinants of price". Cumberland (1994) brings the concepts of interest group acceptability and political feasibility into the debate and argues that the policy approach depends on the ecological damages in the first place. In the case of non-measurable damages, the property-rights approach is sufficient. When damages are measurable, but do not lower the ecosystem productivity, an incentive-based approach (through economic instruments) is applicable. However, when non-sustainable long-term damages are expected to occur, a regulatory approach is followed. For a graphic illustration of this approach, see Figure 1.

Ecological economists follow the precautionary approach arguing a priori that long-term damages are non-sustainable. The property rights and incentive-based approaches can be useful, but only within the boundaries of the politically predefined scale and distributional constraints. The social welfare function, as identified in welfare theory, is still maximised, but subject to different constraints as in environmental economic and neo-institutional economic approaches. Ecological economic approaches are therefore closely linked to individual moralism, but this conclusion is not sufficient. A clear role for government intervention is identified, thereby excluding any links with the radical public choice approach. 


\section{Figure 1 Ecological damage and policy}

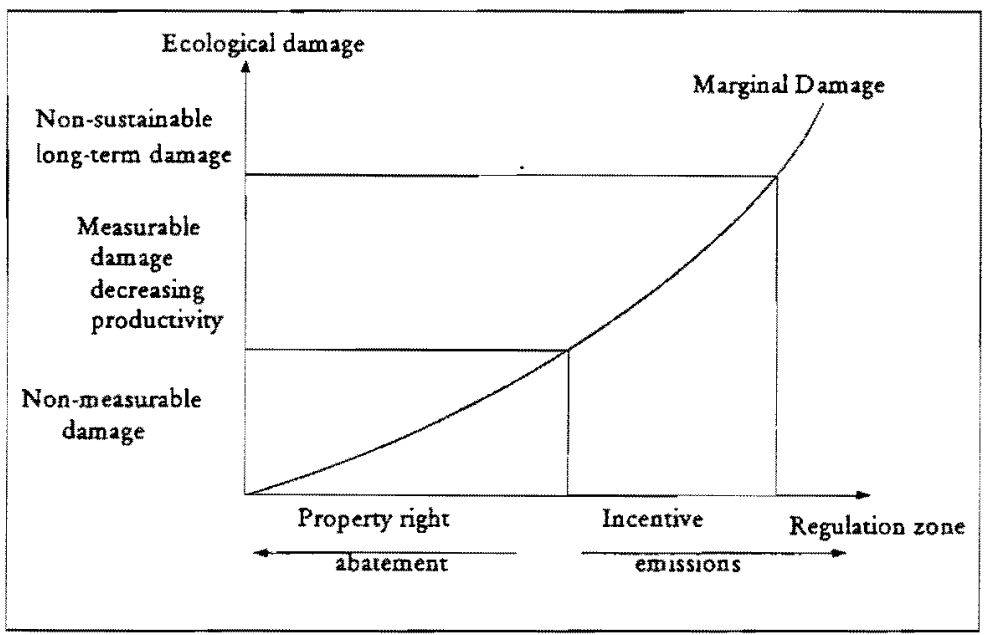

Source: Cumberland (1994)

Although the links have not been made explicitly in the literature, the sequential approach to policy making as promoted by ecological economists such as Daly (1999), is similar to the constitutional economic approach of constitutional and post-constitutional choice (Buchanan, 1991). Politically normative choices on scale and distribution are made on the constitutional level, while the market can allocate resources efficiently within this set of pre-defined constraints. These approaches also link with the policy science approach of focusing on science and professionalised bureaucracies in improving policy design. An example is the emphasis on the scientific derivation of ecological indicators needed for standard-setting. The general lack of attention on the power relations between different actors, and the desire to change the status quo towards a more sustainable society excludes the pluralistic approach to public policy ${ }^{3}$. In summary, the ecological economic approach links best to public policy models through individual moralism, constitutional economics and political science. It can also be argued that the strongest link is with individual moralism from welfare theory, but within the boundaries set by constitutional economic and policy science processes.

One could debate on the relative contributions of various public policy approaches to the various economic theories on the environment, but for the purpose of this paper it is clear that a focus on one specific economic theory and one specific public policy approach leads to a partial interpretation of reality, resulting in turn in a bias, and possibly increased complexity, in policy recommendations. The 
argument also exposes the fact that an ex ante implicit choice of a public policy approach needs to be made, and this reinforces the need for more transparent policy design.

\section{THE NEED FOR A SYSTEMATIC POLICY DESIGN PROCESS}

The public policy approaches discussed so far all view the policy maker as exogenous to a policy support system. Following the work of March and Simon (1958) and Simon (1977), it is assumed that policy making follows a linear and one-dimensional three-stage process of intelligence, design and choice (see Checkland \& Scholes, 1990: 165). In the first stage, problems are identified and data collected; the design-phase consists of planning for possible alternative solutions; and the choice-phase entails the selection of an alternative and the monitoring of its implementation. Based on 12 case histories of policy reform in developing countries, Thomas and Grindle (1990: 1165) refer to a similar linear process in the implementation of policy reforms, following the stages of agenda setting, decision and implementation. Hirschman and Lindblom (1972: 358) also critically refer to the linear process of rational decision making in policy making where objectives or values are first clarified, secondly, alternative means of reaching these objectives are surveyed, thirdly, the consequences of each alternative are identified, and fourthly, each set of consequences is evaluated in the light of the objectives.

The need for an alternative approach to this linear process of policy making has been raised by various scholars (Lindblom, 1959, 1968, 1979; Hirschman \& Lindblom, 1972; Thomas \& Grindle, 1990; De Greene, 1993). Lindblom (1959) argued against proposals for decision-making tools without an explicit recognition of the realities of the political process itself. This point of departure closely corresponds to the argument that the analysis of the political process itself has to be included in a systems approach to policy making. This approach is, in fact, a recognition of the dynamic, changing nexus of decision-making issues and cognitive issues. As pointed out by Hirschman and Lindblom (1972: 357), the critique centres around two assumptions implicit in most of the linear approaches to policy making:

Firstly, that public policy issues can best be understood by attempting to understand them. What does that mean? They cannot be theorised/ generalised?

- Secondly, that there exists sufficient agreement to provide adequate criteria for choosing among possible alternative policies.

On the first assumption, the public policy making process should be viewed as part of a system characterised by continuous feedback. Hirschman and Lindblom were 
writing long before the scientific revolution of dynamic, non-linear systems took place ${ }^{4}$, but the results only seem to confirm their original thesis. It is argued in the literature on dynamic non-linear systems theory that unpredictability and novelty will always be around us, even in the case of deterministic complex systems (Stewart, 1990). None of the public policy approaches, as discussed earlier, referred explicitly to the dynamic complexity of the policy making process. As discussed, the foremost limitation of all the public policies evaluated is the assumption that the context of the public policy problem is not taken into account, i.e. one design fits all. Unpredictability and novelty do not feature meaningfully in these approaches. The recognition, however, that the policy process itself is continuously changing, emphasises the limitations of the perception that the systems approach can only be seen as a decision support tool to a relatively fixed policy process. The policy process co-evolves with the problem situation (De Greene, 1993: 7) and is part of a dynamically interacting systems-field (De Greene, 1993: 133).

The policy process has also long been debated in the development literature. Quarles van Ufford (1993), for example, criticised the lack of attention to the process of policy formulation itself. His criticism focuses on an optimised systems approach, in effect, a closed political system - one where development is presented as manageable, intellectually simple and explicable to an ignorant audience (Van Ufford, 1993: 157). His call for a model, that is a better balance between normative (or ideological) and analytical models, is what is understood in an open, systems approach to the policy making process - one that explicitly recognises the importance of feedback and continuous learning.

On the second point, the linear process of policy making can only take place on the basis that sufficient agreement exists on adequate criteria for choosing among policy alternatives (Hirschman \& Lindblom, 1972: 357). This approach does not advocate either laissez faire or expanded political influence, but is concemed with decision-making and problem-solving activities carried out by the political authorities (Hirschman \& Lindblom, 1972: 364-365). It was already suggested that such agreement is often unlikely as many public policy approaches and different value principles exist with very different implications for policy design, such as economic efficiency and sustainability norms.

In view of the above, the design of economic policy for complex and dynamic problems cannot simply be based on theories on the interface between economics and the environment. There are many different theories, such as environmental economics, ecological economićs, neo-institutional economics and evolutionary economics, that have different frameworks for the design of policy. None of these theories can make a claim to represent absolute truth values; all of them have to internalise increasing spatio-temporal scales of environmental problems and in one 
way or another, both the static and dynamic aspects of political reality need to be taken into account. Public policy approaches are also divided in their approach and based on ideological a priori first principles that are often closely linked to economic or other theories (Schneider \& Ingram, 1997). The design of economic approaches to policy regarding complex and dynamic problems needs to be approached as a process that incorporates feedback and is geared towards continuous learning.

It has been pointed out that the systems approach to sustainable development can take account of both increased complexity and the dynamic processes of change (Clark, Perez-Trejo \& Allen, 1995; De Wit, 2001). The question is whether such an approach can be used for policy making as well. The added value of this approach is that dynamic systems approaches are not only used to enhance the presentation of specific problems to policy makers, but to include interest groups in a learning process of policy making. The design of policy is not confined to analysts, but a far broader approach is taken to both the sources of knowledge and participation. There is thus a need for a policy process that internalises different values within their context, before making a choice on a policy framework. Such a process has to be able to include the many aspects of complexity, but also the dynamic character of policy making for sustainable development. The development of such a framework can best be informed by existing literature on the interface between policy making and complexity theory.

\section{APPROACHES TO COMPLEXITY AND DYNAMICS IN POLICY MAKING FOR SUSTAINABLE DEVELOPMENT}

The search now extends to identifying approaches to policy making that explicitly takes account of complexity and dynamics in real world environmental problems. The question that needs to be answered is how the complexity in economyenvironment-policy systems and the changing realities of policy design can best be approached.

The application of dynamic systems approaches to policy making processes can be informed by various contributions in the literature on systems dynamics, management and organisation (Gill, 1996; Saeed, 1994; De Greene, 1993; Rastogi, 1992; Gardiner \& Ford, 1980; Murthy, 2000; Warfield, 1999, 1994; Vennix, 1999, Checkland \& Scholes, 1990; Checkland, 1981; Senge, 1990; Stacey, 1995; Kelleher, 1970; Busterud, 1977). In addition, and the focus of this paper, a relatively small amount of literature exists on the application of the dynamic systems approach to policy making for environmental problems and/or sustainable development (Saeed, 1998; Roe, 1998; Comfort, 1999; Schoot-Uiterkamp, 1999; Schmoldt \& Peterson, 1999; Wolfenden, 2000; UNDP, 1999). 
Saeed (1998) argues that informing policy making for sustainable development is, given its high complexity and uncertainty, an experiential learning process. The complexity of sustainable deveiopment is captured in a system dynamics model that informs policy makers on appropriate actions. Such a systems dynamics model is dependent on the learning process followed by the modeller.

\section{Figure 2 Kolb's model of experiential learning}

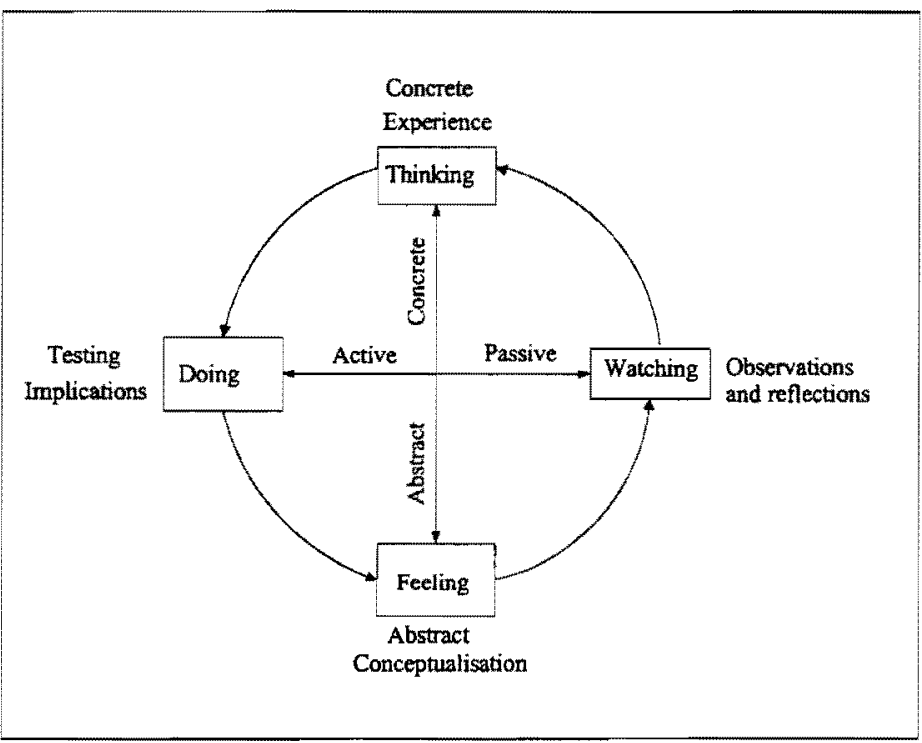

Source: Kolb (1984) as quoted in Saeed (1998)

The core competencies of experiential learning are the learning faculties of watching, thinking, doing and feeling in Kolb's model (see Figure 2) (Saeed, 1998: 407). An important characteristic of these tasks is that they correspond to passivephysical, concrete-cognitive, active-physical and abstract-cognitive domains. Such a display takes account of two basic buman functions, namely the physical and the cognitive, and integration along two primary dimensions, namely the passiveactive and concrete-abstract dimensions. The important conciusion from such an approach is that an understanding of complexity can be facilitated through a leaming model that takes various dimensions of human functioning into account. Saeed $(1998: 407,409)$ likens system dynamics modelling to an art of balancing between these learning faculties.

Roe (1998) also argues that complexity has to be taken seriously when formulating policy, but unlike Saeed (1998), be does not take a system dynamics modelling 
approach. A central problem of public policy analysis has been to find new ways of analysing issues of increasing uncertainty and complexity. Roe suggests the method of triangulation - using various methods, databases, theories and approaches to converge on the complex issue in question. In this method the same set of questions regarding policy issues are asked from multiple perspectives. In this way facets of the problem are identified that may be omitted by other methods. Comfort (1999: 182) welcomes this approach in that it attempts to find appropriate methods that fit the problems, rather than focusing on problems that fit the existing methods. Roe applies this method to the issue of sustainable development and makes recommendations on the basis of selected perspectives on the issue. Without discussing the recommendations in detail, the important finding for the purpose of this paper is, as Comfort (1999: 183) puts it: "... [Roe] puts to rest old arguments of politics versus economics in policy debates and demonstrates afresh that both are central elements in designing workable policy, and neither are likely to define the policy issue accurately". And further (1999: 183): "...implicit in his approach is the recognition that invalid policy analysis contributes to the clamour and confusion in the policy debate. Rather than reducing complexity and increasing clarity of understanding on problems to facilitate action, methods of analysis that provide inaccurate or partial views of a complex policy issue seriously inhibit both understanding and action".

The United Nations Development Programme (UNDP, 1999) used Roe's method to formulate policy for sustainable livelihoods by starting to recognise that such systems are complex and adaptive and can best be analysed on a landscape level. The UNDP (1999: 4) distinguished between two types of policy analysis, namely conventional and complex. Conventional policy analysis is sequential and cumulative; complex policy analysis is interactive and convergent. The former is only applicable in situations "of low environmental uncertainty, relative stability in public (including government) objectives, strong institutional memory in the design and implementation agencies, and sufficient resources to tolerate mistakes in trial and error learning relevant to the issue in question" (UNDP, 1999: 4). Complex policy analysis is further applied to the issue of sustainable livelihoods, using the method of triangulation as discussed in the previous paragraph. The main conclusions are that complex policy issues demand analysis on a case-by-case basis.

These approaches do take account of complexity in policy design and attempt to deal with this through systems modelling and triangulation approaches. This is a step in the right direction, but the limitation with these approaches, and in fact, with most of the other approaches to understanding complexity (see De Wit, 2001: 143-53), is that the policy maker is treated exogenous to the understanding of the policy problem. The focus is on the analyst or scientist to understand and make recommendations on a better understanding of the complexity in the problems at 
hand. Although a huge body of literature recognises the need for consultative, participatory or group learning processes, the overall impression is that these only inform policy making, and does not really endogenise the policy design process within the system under evaluation. However, a limited body of literature is available that explicitly attempts to provide a model to handle both complex issues and design a process wherein various actors (such as policy makers themselves) can be involved.

Checkland and Scholes (1990) apply a soft systems methodology (SSM) trying to 'manage' real-world situations; it is system thinking based and is applicable to taking purposeful action to change real situations constructively. In the SSM it is acknowledged that problem solving can be much more complex and dynamic than allowed for in the more traditional linear approach. Checkland and Scholes (1990: 280-84) distinguish between two modes of SSM. In mode 1 the key word is intervention. SSM is used to do a particular study - it therefore serves as a decision tool for improved management of complex systems. In mode 2, and the one we are interested in, the key word is interaction. The work is done through the use of SSM - real-world feedback is included in a management model of continuous leaming. This does not mean continuous learning about the problem situation per definition, but continuous learning about how to deal with these (new) streams of information in the management process itself. In a model where decision makers are endogenous to the model, mode 2 SSM is more applicable.

The important point is that intervention analysis, social system analysis and political system analysis, which are all aspects of the SSM model, inform an understanding of the problem situation and root definitions of the system ${ }^{6}$. This means that the roles, norms and values of participants are included in the analysis of the system and are subject to continuous learning and revision. The conceptual models are built on the basis of an initial understanding of the system and compared with perceived reality through informal discussions, formal questioning, scenario writing based on operating the models, and attempts to model the real world in the same structure as these conceptual models (Checkland, 1981). If there are major differences, this feedback is internalised in a second round of enquiry. The resulting changes that are proposed are subsequently tested for systematically desirable and culturally feasible changes. Based on experiences with SSM, such a process can best be attempted through participation and interaction between problem solvers and actors in the system, and not only by a team of independent analysts. In summary, learning about complex systems is facilitated through streams of enquiry and the need for dynamic feedback is recognised.

In the same vein, Vennix (1999: 391) further argues that an effective way to address messy problems would be to remove barriers to learning through participation in the construction of the model using methods such as group model 
building. A messy problem is defined as a situation in which opinions in a management team differ considerably (polarisation) (Vennix, 1999: 370). Vennix emphasises the importance of team learning and effective communication to overcome cognitive barriers and accept differences in perceptions that lead to multiple realities. Such team learning would need an effective facilitation. The important contribution for this paper is that the process of decision making in messy problems needs to be facilitated carefully through group model building techniques. There are barriers to cognitive learning and communication that would impede the formulation of solutions for these problems.

\section{THE MULTIPLE LOOP LEARNING FRAMEWORK (MLLF)}

The challenge remains to develop a framework for economic policy on complex and dynamic environmental problems. It is important to think about the meaning of the word framework as this can be interpreted in many different ways. Pollard and Liebeck (1994: 316) defines a framework as "the structural basis of an organisation, the structure of a plan, etc". One can therefore describe a framework as something that approximates the best possible solution as closely as possible. The question: What is best?, however, implies reference to pre-determined criteria outside the framework itself (e.g. economic efficiency, equity, sustainability or survival). The discussion of such a framework would either take one or more of these criteria as the point-of-departure, or fall into a discussion of the relative weights of the different criteria. Such an approach, however, would defy the argument that uncertainty and novelty are features of complex and dynamic systems, and that learning about these systems are the only available option. In such a case the question on a framework for economic policy making for complex and dynamic environmental problems is rather different. The focus changes from finding the best framework available in the circumstances to one where the focus is on the best learning process to facilitate economic policy making. What aspects have to be in place and what questions have to be asked and at what time/stage to guide the process of learning on economic policy making for complex and dynamic environmental problems?

This brings us to the next question: How does one learn? The answer to this question would delimitate some of the issues that need to be included in a learning framework. Kolb's model, as discussed in the last section (and referred to in Figure 2 ), is a useful starting point in this regard. One learns both cognitively and physically, but in a circle of continuous feedback.

Do policy makers also leam in such a way? And, if not, why not? Dror's (1971) reference to a School of Rulers accentuates the fact that such questions have been raised before. There is no reason to believe that policy makers themselves are not 
in a continuous cycle of leaming, or should be in such a leaming process, given the uncertainty and complexity pertaining to policy making issues on complex and dynamic environmental problems. However, the resulting flexible policy making approach could best be guided by a process of learning, in order to reach the best learning process possible.

Are there situations when the learning process is finalised? The point raised that complexity and novelty will always be around us, suggests that such a process cannot ever be finalised. However, it could be argued that the intensity of learning would differ greatly depending on the problem at hand. Based on Kolb's model (Figure 2), one could define learning on two levels:

cognitively focused leaming cycle (vertical axis)

practically focused leaming cycle (horizontal axis).

In the first instance, the added value of analytical work, such as applications of economic theories on the environment would prove to be great. The application of economic analysis on environmental problems would provide important inputs to the policy making process. In case of a practically focused leaming cycle, the marginal added value of cognitive contributions is declining and added value to the policy making process is gained through practical implementation of policy and attempting to recognise patterns in the responding economies. In the problem at hand, and following the distinction between endogenous and exogenous policy making, one could distinguish between a learning framework for policy makers and a learning process for analysts and system dynamic modellers. The latter is a process focusing on the cognitive content of leaming and the former focusing on the practical content of learning. In a sense this is following from the contribution from Checkland and Scholes (1990) who argue that a mode 2 interactive approach is required to deal with the process of policy design itself. Within this meta-level approach one could define a problem-solving approach that takes more cognisance of case-specific analytical issues, as discussed in Checkland \& Scholes's mode 1 approach.

The concept of a learning framework would include a model that facilitates learning itself on different levels. One can refer to the existence of learning cycles within learning cycles, analytical leaming cycles within policy process learning cycles, or multiple loop learning cycles, to represent the changing emphasis on cognitive and physical aspects of different learning events for both analysts and policy makers. The issues raised can be clarified in a simple conceptual framework that captures the most important issues in a framework for economic policy in case of complex and dynamic environmental problems. Such a multiple loop learning framework (MLLF) is illustrated in Figure 2. 
Figure 2 A multiple-loop learning framework (MLLF)

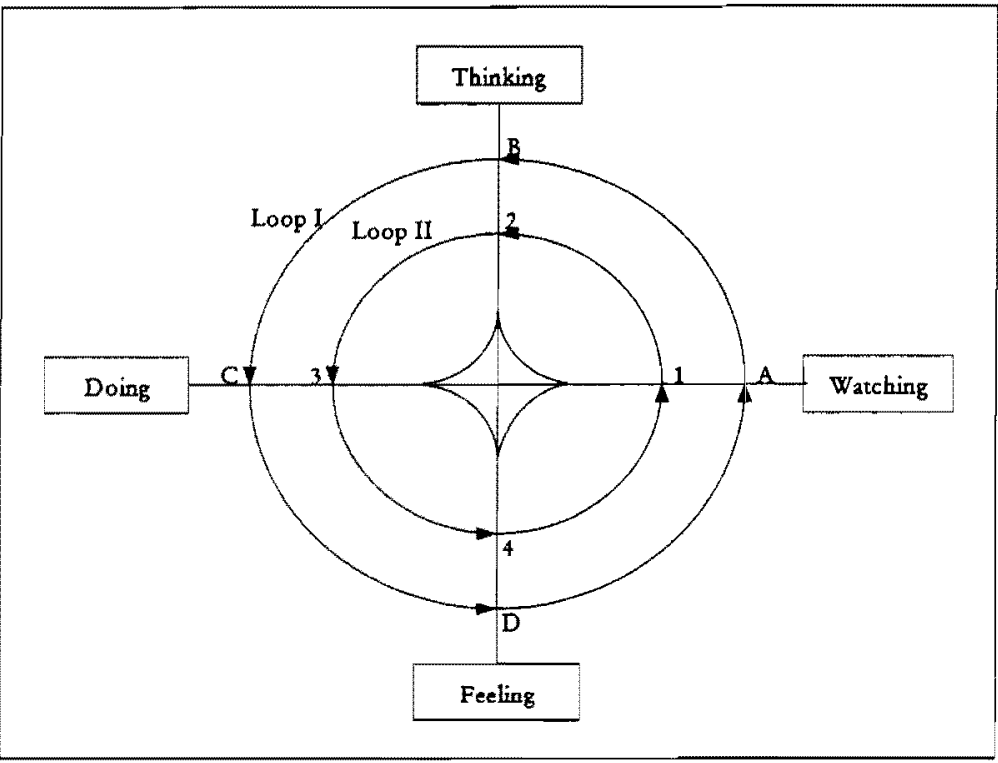

Source: De Wit (2001: 160)

The key research question how best to approach economic policy making for complex and dynamic environmental problems can be answered on a conceptual level with the aid of a MLLF. The MLLF illustrates a number of pertinent issues:

Economic policy making for complex and dynamic environmental problems is first and foremost a learning process, comprising the learning faculties of watching, thinking, doing and feeling.

This learning process has to be facilitated in the best way possible, and the key learning faculties balanced in the right way.

This balance would differ with the problem at hand. In loop I (ABCD), the policy process loop, the focus would be more on the physical and more practical aspects of group processes and facilitation, while loop II (1234), the theoretical learning loop, would be more cognitive, focusing on applications of economic theories on the environment and public policy theories.

These loops, however, are not separate but continuously influence each other when policy making is endogenous to problem resolution. Without elaborating on the interaction between theoretical learning and policy process loops, which is a process of well-facilitated group participation, the important point is that both these loops have to be facilitated for optimal cross-pollination. 
- The nearer to the epicentre (the diamond in the centre), the higher the applicability of high precision science. Closer to the epicentre of the model is the only area where continuous learning is not required, because of low complexity and low randomness. In such cases the problem is too simple to establish a process of policy and analytical learning.

- In situations where the problem under observation is too unorganised to attempt a process of learning, short-cut averages could be used to indicate the macro direction of the system, but at the expense of learning about the key levers of control, change and constraints.

This conceptual framework illustrates a range of key concepts when dealing with complex and dynamic environmental problems. Such types of problems would require continuous learning systems, on both the theoretical and political level and in interaction with each other. In cases of complex and dynamic problems, theoretical studies should be informed by political variables as well and political learning processes should be facilitated as much as possible to optimise on available theoretical information.

A few pertinent questions on especially the economic approach to environmental policy remain. What does the MLLF mean for the economic approach to environmental policy? What are the key learning points of the suggested policy learning framework for economic theories on policy making? A few issues are highlighted:

To base economic approaches to policy making on positive scientific approaches alone impedes the ability to reach the best solutions for complex and dynamic problems. Economic theories on the environment are by definition not scientifically objective. They are based on various different normative premises.

The normative points of departure of various economic theories on the environment are critically examined in an interactive policy learning framework. Economic approaches to environmental policy making are partial representations of reality. The results of such studies are placed in a facilitation process and allocated to the type of problem at hand. Studies that, for instance, demonstrate the relative costs and benefits of alternative approaches to environmental policy making have the highest value in settings where uncertainty and polarisation of environmental problems are minimised.

Solutions to complex and dynamic environmental problems should not be sought in the linear internalisation of external effects alone, but supported and informed by a process of interactive learning and feedback. The focus on the first instance, shifts from internalisation of external effects inside the system to the intemalisation of the policy making process itself in 
addressing complex and dynamic environmental problems. Economics and politics are complementary elements in the design of policy for complex and dynamic environmental problems.

- The opposing policy advices from various theories on economyenvironment interactions are counterproductive. These theories depart from implicit pre-analytical frameworks that do not represent any notion of truth-values by definition. Rather than building theoretical power blocks on the basis of different economic approaches to environmental policy, the challenge is to develop and apply the most relevant approaches in the right problem context. In effect, it is a move away from a universal fit of a particular theory on economy-environment interactions to one of contextual design.

Economic approaches to environmental policy can be leveraged to their highest use when integrated in a well-designed group facilitation process. These processes should at least internalise the following issues ${ }^{7}$ :

- the normative points of departure of interest groups and different theories (partial interpretation of reality)

- the wide range of scientific, economic and political theories on addressing such a problem (type of uncertainty)

- the different interest groups and their values (level of polarisation)

- the spatio-temporal scale (context) of the problem at hand and the best theoretical fit to these problems (type of complexity).

In short, the MLLF does not exclude economic approaches to environmental policy, but is a meta-level process that facilitates the application of such economic approaches to their best use. The important learning points for policy making on complex and dynamic environment problems are that policy makers have to recognise that analysis of the problem will be a learning process unless the type of problem is too simple to justify leaming. The policy makers' choice is:

to slice complex and dynamic environmental problems into simple parts, but at the same time have a well designed policy learning process in place to internalise and facilitate partial analytical results. This choice will be biased towards certain normative criteria (e.g. economic efficiency, sustainability) employed within analytical recommendations, but these are at least placed within the context of a broader model of policy learning.

to have an interactive multiple-loop policy learning framework in place that optimises on learning from the cognitively focused analytical leaming cycle and the practically focused policy leaming cycle.

The choice of a policy design process for complex and dynamic environmental problems will have to be measured against the relative transactional costs of 
such a process. Although the benefits of an interactive learning process, as illustrated by the MLLF, has been pointed out, the further practical question remains what the costs of alternative systems will be. This is a question for further research.

\section{OPPORTUNITIES AND LIMITATIONS OF POLICY DESIGN PROCESS IN THE CASE OF CLIMATE CHANGE}

The direction of economic policy for global climate change is largely summarised in publications from the IPCC, especially those of the working groups on mitigation options (Bruce, Lee \& Haites, 1996; IPCC, 2001). At the time of writing the latest IPCC Working Group III (WG III) contribution to the Third Assessment Report has been accepted, but not approved in detail. Nevertheless, the IPCC's line of thought in this document on economic policy issues could be taken as starting point for an evaluation.

The evaluation is focused on the issue of policy making and decision making on climate change. The pertinent question used as point-of-departure in this review is: What framework is used for approaching mitigation policy on climate change? This question would inevitably produce an answer that could be compared with the MLLF approach, on a conceptual level, as proposed in the previous section.

The IPCC WG III's terms of reference have been to assess the scientific, technical, environmental, economic and social aspects of the mitigation of climate change. Although the mandate has been expanded from a disciplinary assessment of the economic and social dimensions of climate change in the Second Assessment Report (SAR) to an interdisciplinary assessment of the mitigation options in the Third Assessment Report (TAR), this excludes explicit reference to interaction between cognitive analysis of mitigation options and practical policy making processes. The IPCC is very careful to distinguish that it does not make any policy, but only assesses research that is 'policy-relevant'. Although research is a political process, the idea is that policy decisions are made in the UNFCCC COP process, and not by the IPCC ${ }^{8}$.

However, despite possible arguments to broaden the mandate, some useful information in answering the question which approach to economic policy making has been followed, could be found in IPCC WG III material. The following issues are evaluated more specifically:

the nature of the mitigation challenge

the implementation of mitigation options

supportive decision making 


\subsection{The nature of the mitigation challenge}

Following the second assessment report (SAR) (Bruce, Lee \& Haites, 1996), the next IPCC WG III has received the mandate to include equity and sustainability concerns in the assessment. This is a better representation of complexity in the evaluation framework used. However, such an endogenous approach increases the complexity of the system under observation. It has been emphasised in this paper that learning about such complex systems has to be facilitated. This means a well-balanced approach between the practical process of learning and the cognitive content of learning. However, the IPCC WG III line of thinking is to redefine the nature of the mitigation challenge in terms of its complexity focusing mainly on the content of the problem, but the process of achieving such learning is not elaborated on in detail. In short, the focus in dynamic complex problems is changing from an understanding of the nature of the problem to support policy making towards an interaction with policy makers and other actors in a dynamic policy making process. It is recommended that economic policy makers on climate change evaluate the applicability of results in the science of complexity and its application to policy making processes.

The approach to uncertainty and irreversibility taken in IPCC WG III work would largely determine whether one would accept decision analytical tools or more processional approaches to inform mitigation policies for climate change. In any situation where time is treated as asymmetrical, one can talk about some type of implied irreversibility. Whether future events are perceived to be predictable depends on this type of irreversibility. Unpredictable processes are those where novelty is emerging over time or where there is an unknown end to future activities. The question relevant for the IPCC WG III work is which type of irreversibility should be used for decision analysis of various problems related to mitigation policy. An analysis of some issues at certain spatiotemporal scales might be too uncertain to employ probabilistic outcomes. In such cases, it would be an option to acknowledge complexity and manage the problem-solving process accordingly. When the design of mitigative policies is formulated as an open-ended, soft system, an interactive learning process can provide various inputs for problem solving in the face of uncertainty and irreversibility.

\subsection{The implementation of mitigation options}

The assessment of alternative policy instruments in terms of specific criteria is an open-ended debate. The design of optimal policy mixes is, in practice, often still static in orientation and dependent on the chosen normative criteria, such as economic efficiency or sustainability. Despite a recognition in IPCC WG III work of the importance of interest groups and policy makers themselves in the 
design of policy instruments, an analysis of the policy design process that underlies the selection of criteria and the relative weights attached to these criteria in a learning framework, is an omission in this work so far. The increased complexity of policy design for climate change (number of policy instruments, number of criteria, number of actors) raises questions on the analysis of such processes. It is recommended that the option of viewing the problem as an interactive leaming process that needs to be facilitated in the best way possible, be evaluated.

\subsection{Supportive decision making}

There is no clear, unified, philosophical, theoretical or practical framework that could guide policy making in all aspects of policy design. Various decision support tools do exist, but neither on its own would provide a comprehensive overview and recommended action on policies for climate change. IPCC WG III acknowledges this and makes a sensible, reserved judgement on the usefulness of these tools. However, the challenge remains to develop a systematic policy design process that utilises these tools in the right context - answering the right questions at the right time. Again, the right balance between the cognitive content of decision-making tools and the practical process wherein these tools are utilised, is one worth exploring.

The discussion on decision-making frameworks is limited to providing advice to policy makers that excludes interactive learning processes between cognitive analysis and practical policy making processes. At best, the process of international agreements is analysed in terms of the design of a framework for institutions or to look at procedures of decision making at various levels. Although these are important contributions in their own right, a facilitated learning process that makes the most of cognitive inputs and provides inputs for further cognitive development, is an omission in the focus on an analysis of policy options as such. It is recommended that the focus of research on process analysis is broadened from an analysis on the links between policy options and the structure of agreements to one where the parameters for best cognitivepractical interaction are spelt out and implemented. An additional research question would therefore be: How can one best facilitate the interactive process of learning on mitigation policies for climate change?

\section{CONCLUSIONS}

In this paper it was attempted to formulate a conceptual framework for economic policy making on complex and dynamic environmental problems. Such a framework has been proposed in the form of a multiple-loop learning 
framework (MLLF). The multiple loops consist of a practical policy making learning framework, and a theoretical analytical learning framework. These learning processes influence each other. The processes of learning on both levels need to be facilitated and informed by tools such as group model building and systems dynamics models.

An attempt to understand a problem is limited to situations of low complexity and low randomness, such as non-living, engineering systems, consumer choices between a small number of products and the growth of a plant under controlled conditions. An attempt to ex ante understand a dynamic and complex public policy issue, such as economic policy making in the case of climate change, with large numbers of interest groups and different value systems, different cognitive frameworks (for example different scientific, economic and public policy theories), different spatio-temporal scales and many possible policy instruments, would underestimate the unpredictability and novelty inherent in complex systems.

An evaluation of developments in the approach to economic policy on global climate change reveals that it falls short in approaching as a complex and dynamic environmental problem in the first place, as would be evident through an interactive policy learning process. Although the complexities of the problem are more and more internaiised, there is no real learning process that places these ideas into the right context. The decision analytical tools that are developed are often focused on complex, but closed systems. In addition, normative criteria, such as economic efficiency or sustainability, can play an important role in shaping the debate, but it is evident that the debate on economic policy for global change often resorts to counterproductive theoretical infighting as based on different $a$ priori chosen criteria. The selection of criteria for further analysis, however, should be the result of an interactive leaming process, as reality is larger than these theories can comprehend. It is therefore recommended that the application of interactive learning frameworks to real-world economic policy making for complex and dynamic environmental problems is an area for further research.

\section{ENDNOTES}

1 This paper is largely based on the author's D.Com thesis and funding from the CSIR is gratefully acknowledged.

2 For a more detailed discussion see Kruger \& de Wit (2002).

3 Hanna et al. (1997) applied the institutional focus on property right structures to ecological problems, but this is not the general case in the subject field of ecological economics. 
4 See Prigogine and Stengers (1984), Stewart (1990) and Waldrop (1994) for background information.

5 For a comprehensive review see de Wit (2001:141-53)

6 Root definitions are concise verbal definitions expressing the nature of purposeful activity systems regarded as relevant to exploring the problem situation. A full root definition would take the form: do $X$ by $Y$ in order to achieve $Z$.

7 For a comprehensive discussion on these issues see de Wit (2001: 155-9).

8 I am grateful to an anonymous reviewer who alerted me to this point.

\section{REFERENCES}

1 ANDERSON, T.L. \& HILL, P.J (1995) Wildlife in the Marketplace. The Political Economy Forum, Lanham, Maryland: Rowman \& Littlefield.

2 ANDERSON, T.L. \& LEAL, D.R. (1991) Free Market Environmentalism, Pacific Research Institute for Public Policy, San Fransisco, Boulder etc.: Westview.

3 BLAUG, M. (1980) The Methodology of Economics, Cambridge: Cambridge University Press.

4 BLAUG, M. (1992) The Methodology of Economics, Cambridge: Cambridge University Press.

5 BOADWAY, R. (1974) "The Welfare Foundations of Cost-Benefit Analysis", Economic Journal, 84: 926-39.

6 BOLAND, L.A. (1982) The Foundations of Economic Method, London etc.: Allen \& Unwin.

7 BRENNAN, G. \& BUCHANAN, J.M. (1985) The Reason of Rules, Constitutional Political Economy, Cambridge etc.: Cambridge University Press.

8 BROMLEY, D.W. (1991) Environment and Economy. Property Rights and Public Policy, Oxford, UK \& Cambridge, USA: Basil Blackwell.

9 BROMLEY, D.W. (2000) "The Two Realms of Reason: Calculation and Sentiment", Paper presented at the $7^{\text {th }}$ Ulvön conference on Environmental Economics, Ulvön, Sweden, June 18-21.

10 BRUCE, J.J., LEE, H. \& HAITES, E.F. (eds.) (1996) "Climate Change 1995. Economic and Social Dimensions of Climate Change". Contribution of Working Group III to the Second Assessment Report (SAR) of the Intergovernmental Panel on Climate Change (IPCC). Cambridge: Cambridge University Press.

11 BUCHANAN, J.M. (1987) Economics. Between Predictive Science and Moral Philosophy, compiled by R.D. Tollison. \& V.J. VanBerg. College Station: Texas A\&M University Press. 
12 BUCHANAN, J.M. (1991) Constitutional Economics, Cambridge, Mass.: Basil Blackwell.

13 BUSTERUD, J. (1977) "IIASA and the Policy Maker: Integrating the Research Function into Decision Making Research Memoranda", RM-77045, International Institute for Applied System Analysis (IIASA).

14 CALDWELL, B. (1982) Beyond Positivism, London: Allen \& Unwin.

15 CHECKLAND, P. (1981) Systems Thinking, Systems Practice, Chichester: Wiley.

16 CHECKLAND, P. \& SCHOLES, J. (1990) Soft Systems Methodology in Action, Chichester: Wiley.

17 CLARK, N., PEREZ-TREJO, F. \& ALLEN, P. (1995) Evolutionary Dynamics and Sustainable Development. A Systems Approach, Aldershot, UK \& Brookfield, US: Edward Elgar.

18 CLINE, W.R. (1992) The Economics of Global Warming, Washington, D.C.: Institute for International Economics (IIED).

19 COMFORT, L.K. (1999) Book review: "Taking Complexity Seriously: Policy Analysis, Triangulation, and Sustainable Development", Journal of Policy Analysis and Management, 18(1): 181-4.

20 CUMBERLAND, J.H. (1994) "Ecology, Economic Incentives, and Public Policy in the Design of a Transdisciplinary Pollution Control Instrument", in Toward Sustainable Development. Concepts, Methods and Policy, edited by J.C.J.M. van den Bergh \& J. van der Straaten. International Society for Ecological Economics (ISEE). Washington, D.C.: Island Press.

21 DALY, H.E. (1992) "Allocation, Distribution, and Scale: Towards an Economics that is Efficient, Just and Sustainable, Ecological Economics, 6: 185-93.

22 DALY, H.E. (1999) "Reply to Marcus Stewen", Ecological Economics, 30: $1-2$.

23 DE GREENE, K. (1993) A Systems-Based Approach to Policy Making. Boston: Kluwer.

24 DE WIT, M.P. (2001) "Economic Policy Making for Complex and Dynamic Environmental Problems: a Conceptual Framework", D. Com. thesis, University of Pretoria, Pretoria.

25 DROR, Y. (1971) Design for Policy Sciences, New York: American Elsevier.

26 EICHNER, A.S. (ed.) (1983) Why Economics is Not Yet a Science. London: MacMillan.

27 FANKHAUSER, S. (1995) Valuing Climate Change: The Economics of the Greenhouse, London: Earthscan.

28 FRIEDMAN, M. (1953) Essays in Positive Economics, Chicago: University of Chicago Press. 
29 GARDINER, P.C. \& FORD, A. (1980) "Which Policy Run is Best, and Who Says So?" in System Dynamics: TIMS Studies in the Management Sciences, A.A. Legasto, Forrester, J.W. \& Lyneis, J.M. (eds.) Amsterdam etc.: North-Holland.

30 GILL, R. (1996) "An Integrated Social Fabric Matrix/Systems Dynamics Approach to Policy Analysis", Systems Dynamics Review, 12(3): 167-81.

31 GUNNINGHAM, N., \& GRABOSKY, P. (with Sinclair, D.) (1998) Smart Regulation. Designing Environmental Policy, Oxford: Claredon.

32 HAHN, F. \& HOLLIS, M. (eds.) (1979) Philosophy and Economic Theory, Oxford: Oxford University Press.

33 HAHN, R.W. (1989) "A Primer on Environmental Policy Design", Fundamentals of Pure and Applied Economics. Government Ownership and Regulation of Economic Activity Section, vol. 34, Chur, etc.: Harwood Academic Publishers.

34 HANNA, S., FOLKE, C. \& MÄLER, K-G. (eds.) (1996) Rights to Nature: Ecological, Economic, Cultural and Political Principles of Institutions for the Environment, Washington, D.C.: Island Press.

35 HIRSCHMAN, A. \& LINDBLOM, C. (1972) "Economic Development, Research and Development, Policy Making: Some Convergent Views", in Systems Thinking, Emery, F.E. (ed.). Harmondsworth: Penguin.

36 INTERNATIONAL PANEL ON CLIMATE CHANGE (IPCC), (2001) "Climate Change 2001", Contributions of Working Group III to the Third Assessment Report of the IPCC. Cambridge: Cambridge University Press.

37 IN'T VELD, R.J. \& KRAAN, D.J. (1991) "Introduction", in Environmental Protection: Public or Private Choice, (eds.) by D.J. Kraan \& R.J. in't Veld. Dordrecht: Kluwer.

38 KEEN, P.G.W. \& SCOTT-MORTON, M.S. (1978) Decision Support Systems, New York: Addison-Wesley.

39 KELLEHER, G.J. (ed.) (1970) The Challenge to Systems Analysis; Public Policy and Social Change, New York etc.: Wiley.

40 KEYNES, J.N. (1917) The Scope and Method of Political Economy, London: A.M. Kelley.

41 KOLB, D.A. (1984) Experiential Learning, Englewood Cliffs, N.J.: Prentice-Hall.

42 KRUGER, A.J. \& DE WIT, M.P. (2002) "A Philosophical Inquiry into Sustainability Assessment as Applied to Agriculture", Paper presented a Forum for Economics and Environment (FEE) conference, V\&A Waterfront, Cape Town, 11-12 February.

43 LINDBLOM, C.E. (1959) "The Science of Muddling Through", Public Administration Review, 19(2): 79-88.

44 LINDBLOM, C.E. (1968) The Policy Making Process, New Jersey: Prentice-Hall. 
45 LINDBLOM, C.E. (1979) "Still Muddling, not yet Through", Public Administration Review, 39: 517-26.

46 MARCH, J.G. \& SIMON, H.A. (1958) Organization, New York: Wiley.

47 MURTHY, P.N. (2000) "Complex Societal Problem Solving: A Possible Set of Methodological Criteria", Systems Research and Behavioural Science, 17(1): 73-101.

48 NORDHAUS, W.D. (1991) "To Slow or Not to Slow: the Economics of the Greenhouse Effect", Economic Journal, 101, July: 920-37.

49 OPSCHOOR, H. \& Tumer, K. (eds.) (1994) Economic incentives and environmental policies: principles and practice. Dordrecht etc.: Kluwer.

50 PEET, J. 1992. Energy and the ecological economics of sustainability. Washington, D.C. \& Covelo, California: Island Press.

51 POLLARD, E. \& LIEBECK, H. (1994) The Oxford Paperback Dictionary. ( $4^{\text {th }}$ ed.) Oxford etc.: Oxford University Press.

52 PRIGOGINE, I. \& STENGERS, I. (1984) Order Out of Chaos. Man's New Dialogue with Nature, New York: Bantam.

53 QUARLES VAN UFFORD, P. (1993) "Knowledge and Ignorance in the Practices of Development Policy", in An Anthropological critique of Development: The Growth of Ignorance, Hobart, H. (ed.) London: Routledge.

54 RASTOGI, P.N. (1992) Policy Analysis and Problem-Solving for Social Systems - Toward Understanding, Monitoring, and Managing Complex Real World Problems, Sage.

55 ROE, E.M. (1998) Taking Complexity Seriously: Policy Analysis, Triangulation, and Sustainable Development, Boston: Kluwer.

56 SAEED, K. (1994) Development Planning and Policy Design: A Systems Dynamics Approach, Aldershot etc:: Avebury.

57 SAEED, K. (1998) Towards Sustainable Development: Essays on Systems Analysis of National Policy, $\left(2^{\text {nd }}\right.$ ed.) Aldershot etc.: Ashgate.

58 SCHMOLDT, D.L. \& PETERSON, D.L. (1999) "Analytical Group Decision Making in Natural Resources: Methodology and Application", Forest Science, 46(1): 62-75.

59 SCHNEIDER, A.L. \& INGRAM, H. (1997) Policy Design for Democracy, University Press of Kansas.

60 SCHOOT-UITERKAMP, A.J.M. (1999) "Book Review: Taking Complexity Seriously: Policy Analysis, Triangulation, and Sustainable Development", Journal of Environmental Policy and Planning, 1(3): 2667.

61 SEN, A.K. (1970) Collective Choice and Individual Welfare, Amsterdam: North-Holland.

62 SENGE, P. (1990) The Fifth Discipline: The Art and Practice of the Learning Organisation, New York: Currency/Doubleday. 
63 SIMON, H.A. (1977) The New Science of Management Decision, Revised ed. Englewood Cliffs, NJ: Prentice-Hall.

64 STACEY, R. (1995) "The Science of Complexity: An Alternative Perspective for Strategic Change Processes", Strategic Management Journal, 16(6): 477-95.

65 STERNER, T. (1994) "Policy Instruments for a Sustainable Economy", in Economic Policies for Sustainable Development, Sterner, T. (ed.). Dordrecht: Kluwer.

66 STEWART, I. (1990) Does God Play Dice? The New Mathematics of Chaos, London: Penguin.

67 THOMAS, J.W. \& GRINDLE, M. (1990) "After the Decision: Implementing Policy Reforms in Developing Countries", World Development, 18(8), August: 1163-81.

68 UNITED NATIONS DEVELOPMENT PROGRAMME (UNDP) (1999) Policy Analysis and Formulation for Sustainable Livelihoods, Internet: http://www.undp.org/sl/documents/strategy_paper.../policy_analysis_and formulation.html, Access: 2 June 2000.

69 VENNIX, J.A.M. (1999) "Group Model-Building: Tackling Messy Problems", Systems Dynamics Review, 15(4): 379-401.

70 WALDROP, M.M. (1994) Complexity. The Emerging Science at the Edge of Chaos and Order, London: Penguin.

71 WARD, B. (1972) What's Wrong with Economics? New York: Basic Books.

72 WARFIELD, J.N. (1994) A Science of Generic Design: Managing Complexity through Systems Design, $\left(2^{\text {nd }}\right.$ ed.) Iowa State University Press/Ames.

73 WARFIELD, J.N. (1999) "Twenty Laws of Complexity: Science Applicable in Organisations", Systems Research and Behavioural Science, 16(1): 3-40.

74 WOLFENDEN, J. Policy Analysis for Ecologically Sustainable Development Research outline for Ph.D. Internet: http://www. personal.une.edu.au/ jwolfend/jawsphd.htm. Access: 23 August 2000. 